\title{
Assessment of the SWAT model to simulate a watershed with limited available data in the Pampas region, Argentina
}

\author{
Martín Romagnolia,*, Margarita Portapila ${ }^{\mathrm{a}}$, Alfredo Rigalli ${ }^{\mathrm{b}}$, Gisela \\ Maydana $^{\mathrm{a}}$, Martín Burgués ${ }^{\mathrm{a}}$, Carlos M. García ${ }^{\mathrm{c}}$ \\ ${ }^{a}$ French Argentine International Center for Information and Systems Sciences. National \\ Scientific and Technical Research Council of Argentina. Rosario National University. \\ Ocampo and Esmeralda, S2000 Rosario, Argentina. \\ ${ }^{b}$ Bone Biology Laboratory. Faculty of Medical Sciences. Rosario National University. Santa \\ Fe and Francia, S2002 Rosario, Argentina. \\ ${ }^{c}$ Center for Studies in Water Technology. Córdoba National University. Bv. Dr Juan \\ Filloy s/n, Ciudad Universitaria, 5000 Córdoba Argentina
}

\begin{abstract}
Argentina has been among the world leaders in the production and export of agricultural products since the 1990s. The Carcarañá River Lower Basin (CRLB), a cropland of the Pampas region supplied by extensive rainfall, is located in an area with few streamgauging and other hydrologic/water-quality stations. Therefore, limited hydrologic data are available resulting in limited water-resources assessment. This work explores the application of Soil and Water Assessment Tool (SWAT) model to the CRLB in the Santa Fe province of the Pampas region. The analysis of field and remote-sensing data characterizing hydrology, water quality, soil types, land use/land cover, management practices, and crop yield, guarantee a comprehensive SWAT modeling approach. A combined manual and automated calibration and validation process incorporating sensitivity and uncertainty analysis is performed using information concerning interior watershed processes. Eleven N/P fertilizer rates are selected to simulate the impact of $\mathrm{N}$ fertilizer on crop yield, plant uptake, as well as runoff and leaching losses. Different indices (partial factor productivity, agronomic effi-
\end{abstract}

\footnotetext{
* Corresponding author

Email address: romagnoli@cifasis-conicet.gov.ar (Martín Romagnoli)
} 
ciency, apparent crop recovery efficiency of applied nutrient, internal utilization efficiency, and physiological efficiency) are considered to assess nitrogen-use efficiency. The overall quality of the fit is satisfactory considering the input data limitations. This work provides, for the first time in Argentina, a reliable tool to simulate yield response to soil quality and water availability capable to meet defined environmental targets to support decision making on planning public policies and private activities on the Pampas region.

Keywords: crop yield calibration, fertilizers, nitrogen use efficiency, Pampas region, ungauged basin, SWAT

\section{Introduction}

Mankind will be facing great challenges in the next few decades. The world population reached 7 billion in 2012 and is expected to exceed 9 billion by 2050 (FAO, 2015). A global demand for food and water will increase with expected population (Ray et al., 2013). Historically, Argentina has been among the world leaders in the production and export of agricultural products. Recent studies show that over the last 15 years degradation and soil disturbance are taking place in the country because of the re-agriculturalization of Latin America's economies driven by international market prices and Chinese foreign investments (Gallagher et al., 2012; Young, 2006). Agricultural practices determine food production level and, to a large extent, the state of the global environment. Agro-industry adds globally appreciable amounts of nitrogen (N) and phosphorus (P) to terrestrial ecosystems. High applications of fertilizers can reduce ecosystem capacity to provide goods and services (Tilman et al., 2002). World demand for $\mathrm{N}$ fertilizers increased by 2.3 million tons annually from 2002 to 2012 and is expected to reach 115.9 million tons in 2016 (FAO, 2015). The predominant effect of agriculture in $\mathrm{N}$-derived contamination results in that fertilizers account for $63 \%$ of all anthropogenic sources of nitrogen. The misuse of fertilizers can create serious environmental problems (Galloway et al., 2008; Rocha et al., 2015) through mechanisms such as leaching, surface runoff 
and denitrification (van Grinsven et al., 2015). Challenges in food production must be addressed in a comprehensive framework. Therefore, holistic analyses of soil-water-plant quality, stress tolerance and environmental benefits of various practices are needed.

The Carcarañá River Lower Basin (CRLB) (Fig. 1) is a cropland with extensive rainfall of the Pampas region that produces primarily soybeans, wheat and corn. Little hydrological data and water-resources assessments are available in the basin. This work describes the application of Soil and Water Assessment Tool (SWAT) model to the CRLB in Santa Fe province with a threefold objective: (i) to assemble all the required input information to run the SWAT model, (ii) to calibrate and validate the model for the period 1993-2013, and (iii) to assess the effect of different fertilizer application rates on yield and nutrient loss.

A reliable tool capable to simulate yield response to soil quality and water availability in order to meet defined targets (such as biomass quality, surface and groundwater quality, soil quality, and sediment production) will support decision making in planning public policies and private agricultural activities. A calibrated CRLB model would be of interest to government agencies, commodity firms, and agricultural producers.

\section{Study area: Carcarañá River Lower Basin in Santa Fe province}

The Carcarañá River Basin encompasses an area of approximately 50,000 $\mathrm{km}^{2}$ extending into the central-southeastern region of Córdoba province and the southern region of Santa Fe province. The Carcarañá River flows east through Córdoba province, taking its name after the confluence of the Ctalamochita and Chocancharava Rivers and then turns northeast into Santa Fe province before discharging into the Paraná River. Climate is characterized as hot with humid summers and generally mild winters. The average annual precipitation reaches $900 \mathrm{~mm}$ and average annual temperature is about $16^{\circ} \mathrm{C}(\mathrm{SSRH}, 2010)$. Approximately 1.7 million people live within the basin and farming activities strongly dominate the economy. The combination of arable soils and abundant 


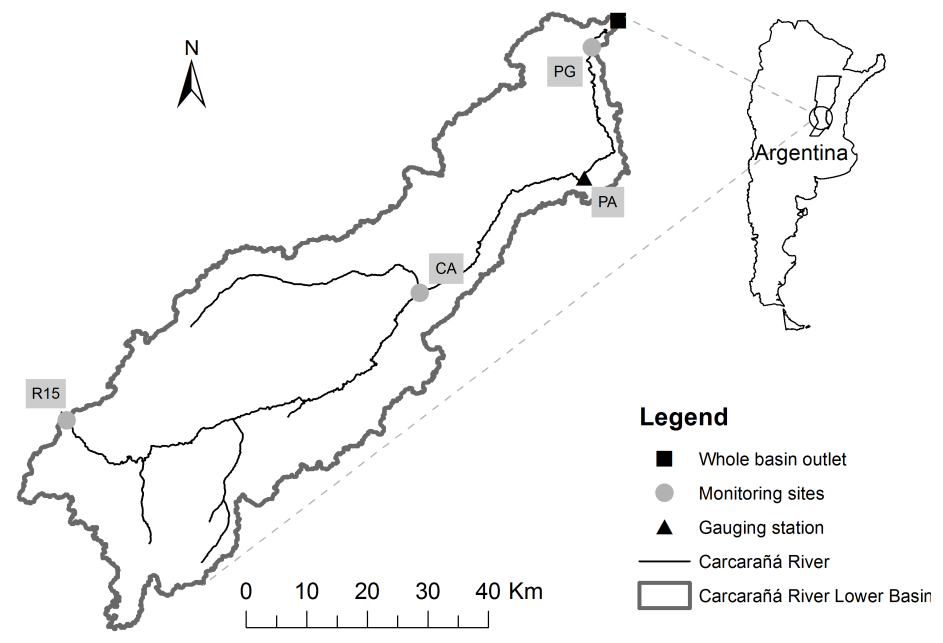

Figure 1: Carcarañá River lower basin in the Santa Fe province. Pueblo Andino station (PA) is the only active streamflow-gauging station in the watershed. Carcarañá (CA), Puerto Gaboto (PG) and Ruta15 (R15), are monitoring sites added to provide flow characteristics (bathymetry, discharge, velocity, and depth) and water-quality data.

rainfall create one of the best agricultural areas of Argentina (Solbrig, 1996).

This work focuses on the CRLB in Santa Fe province. The study area covers about 3,200 $\mathrm{km}^{2}$ (Fig. 1) that includes 20 small towns and villages (Arequito, Cañada de Gómez, Carcarañá, Oliveros, Pueblo Andino, Puerto Gaboto, among the most important ones) distributed into 6 counties (Belgrano, Caseros, Iriondo, San Jerónimo, San Lorenzo and San Martín). In this drainage area, the river is $140 \mathrm{~km}$ long and the mean basin slope is less than 1\% (elevation ranges between 130 and $20 \mathrm{~m}$ above sea level, Figure 2a). The drainage system includes the Cañada de Gómez and Los Leones Rivers and Serodino and Salto Grande Canals. Because of the flat topography surpluses are artificially drained through a system of legal and illegal open field ditches.

\section{Materials and methods}

Because of the limited available data in the CRLB, soft data sets were developed from literature sources and a basic understanding of processes within the 
study area. Soft data are defined as information on individual processes within a balance that may not be directly measured in the study area. Examples of soft data include regional estimates of baseflow ratios or evapotranspiration, average depths of water tables, average annual runoff coefficients for various land uses, annual rates of denitrification from research plots found in the literature, event mean concentrations, nutrient/sediment export coefficients, sediment deposition from reservoir sedimentation studies, average crop/vegetation leaf area index, county crop yields, and others. Seibert and McDonnell (2002) argued that soft data represent a new dimension to the model calibration process that could: (i) enable dialog between experimentalists and modelers, (ii) be a formal check on the reasonableness and consistency of internal model structures and simulations, and (iii) specify realistic parameter ranges usually ignored in today's automatic calibration routines. Highlighting that model performance increased appreciably when using soft data, and parameter uncertainty was reduced by $60 \%$ on average, with the introduction of soft data multi-criteria calibration. Soft data developed in this work include inlet flow at the R15 section, identification of land use, N and P load at the R15 and PA stations (Fig. 1), and values for nitrogen-use efficiency (NUE).

\subsection{SWAT model}

SWAT is a well-established and nonproprietary hydrologic/water quality tool developed by the U.S. Department of Agriculture-Agriculture Research Service (USDA- ARS) (Arnold et al., 1998; Neitsch et al., 2011). Historical development and applications of this model can be found in Arnold et al. (2012b), Bressiani et al. (2015) and Gassman et al. (2007).

SWAT is a continuous time, semi-distributed, process-based model that operates on a daily time-step and is designed to simulate the effect of landmanagement practices on water, sediment and agricultural yields in large complex basins with varying soils, land use and management conditions over long time periods (from years to decades) (Neitsch et al., 2011).

In the SWAT model, a basin is divided into multiple subbasins, which are 
then further subdivided into hydrologic response units (HRUs) that consist of a unique combination of soil, slope, land use, and land management. Water balance is the driving force behind all processes and the HRU is the smallest landscape component used for computing the hydrologic processes. These processes are divided into two phases: a land phase where the model simulates catchment loadings of flow, sediment, nutrients, and pesticides from each HRU, which are then area-weighted to subbasin level; and an in-stream phase, where SWAT routes catchment loadings from each subbasin through the channel network.

A single plant growth model is used in SWAT to simulate different land cover types including a large data base of crop types. The plant growth model is used to assess removal of water and nutrients from the root zone, transpiration, and biomass/yield production. Planting, harvesting, tillage passes, and nutrient and pesticide applications can be simulated for each cropping system with specific dates.

Once the loading of water, sediments, nutrients, and pesticides from all HRUs have been determined to the subbasin level, they are routed through channels, ponds, reservoirs, and wetlands to the watershed outlet. A brief description of SWAT model components can be found in Tuppad et al. (2010). SWAT2012 version (Arnold et al., 2012a) with ArcSWAT geographic information system (GIS) interface (Olivera et al., 2006) was used in this work.

\subsection{Climate database}

There are few streamflow-gauging and other station types present in the Carcarañá River Basin. Currently (2016), there are two active climate stations in the basin (area approximately $50,000 \mathrm{~km}^{2}$ ). Only one of these stations is located in the CRLB (Oliveros station - 32 30 '00"S 6051'00"W). This station is operated by the National Institute of Agricultural Technology (Instituto de Tecnología Agropecuaria/INTA). This limitation in available streamflow and climate information constrain the accuracy of the numerical simulation performed in this work. 
The climate information required by SWAT, which includes daily values of precipitation, maximum and minimum air temperature, solar radiation, relative humidity and wind speed, were obtained from Climate Forecast System Reanalysis (CFSR) global meteorological dataset (Dile and Srinivasan, 2014; Fuka et al., 2014). CFSR climate data from six stations across CRLB served as meteorological input variables for the period 1993-2010. The SWAT model in-built weather data simulator, WXGEN, was used to complete climate data for the period 2011-13.

\subsection{Digital elevation model/Topography}

The basin, subbasins and channels network were delineated in this work using terrain processing tools of the ArcHydro module for ArcGIS based on Shuttle Radar Topography Mission (SRTM) digital elevation data with 90x90 $\mathrm{m}$ grid cell resolution (CGIARCSI, 2014) (Fig. 2a). The subbasin delineation was detailed enough to capture appreciable topographic variability within the basin. The number of subbasins chosen to simulate the entire basin depended on the spatial detail of available input data and recommendations given by Jha et al. (2004) regarding sensitivity of SWAT to basin subdivision on flow and nutrient simulation results. The river path delineated from surface topography was verified with information provided by the Undersecretary for Water Resources within the Ministry of Interior of Argentina (Subsecretaría de Recursos Hídricos de la Nación/SSRH) (SSRH, 2010).

\subsection{Soils}

Soil cartography started in Argentina as a political need for the implementation of a tax reform. As a consequence, in the 1960s, an ambitious project started towards increasing knowledge of soil resource. The project was named "Soil Map Project of the Pampean Region" (Plan Mapa de Suelos de la Región Pampeana), and was carried out by INTA. The primary products of this project were printed soil maps of the Pampas region at a 1:50,000 scale. (INTA, 1988; Moscatelli and Pazos, 2000). Given that digitalized soil maps of the study area 


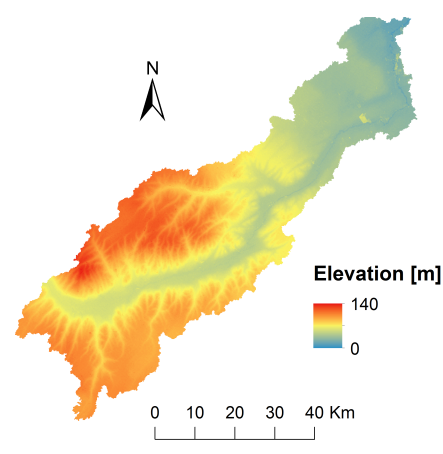

(a) Digital elevation data

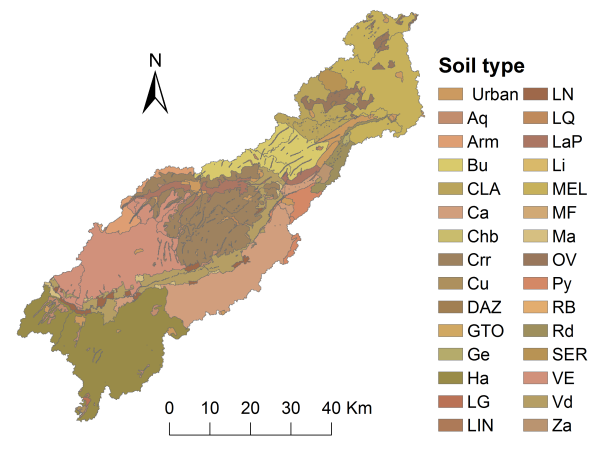

(b) Soil type

Figure 2: Carcarañá River lower basin in the Santa Fe province, (a) digital elevation data, (b) soil type.

are currently (2016) available at a 1:500,000 scale, additional effort was needed to create a digital version of printed soil maps at a 1:50,000 scale. The study area covered eight printed soil survey maps: Cañada de Gómez and Rosario (3360-13 and 14), Berabevú (3363-30), Melincué (3360-25), Totoras and Serodino (3360-7 and 8), Cruz Alta (3363-24), Casilda (3360-19), Maizales (3363-24) and Marcos Juárez (3363-17). Each map was scanned to construct the CRLB map. Once the entire raster data were prepared, the entire soil survey map was vectorized in order to enter it into a GIS.

Taxonomy of the study area is characterized by the presence of Typic Argiudoll (83\%), Aquic Argiudoll (3\%), Typic Argialboll (4\%) and Typic Natralboll (6\%) soils that belong to the Mollisol (96\%) order, and Typic Natracualf (2\%) soil that belongs to the Allfisol order. The major soil series include fine-silty Hansen (Ha, 19\%), Villa Eloisa (VE, 13\%) and Villada (Vd, 6\%), and fine-clayey Maciel (MEL, 13\%), Correa (Crr, 12\%), Casilda (Ca, 11\%), Bustinza (Bu, 6\%), Clason (CLA, 5\%), La Patria (LaP, 3\%), Oliveros (OV, 2\%) and Peyrano (Py, $2 \%$ ) (Fig. 2b).

The database containing detailed information about physical properties and hydrological parameters for different soil horizons was completed using avail- 
able soil data and pedotransfer functions (PTFs). INTA soil maps data contain textural soil information for up to nine soil layers. Depth from soil surface to bottom of each layer, organic carbon content and particle size distribution were obtained from soil surveys provided by INTA (INTA, 1988). Bulk density, water content (i.e., permanent wilting point and field capacity) and saturated hydraulic conductivity were estimated using point pedotransfer methods implemented in Rosetta and SoilPar software (Acutis and Donatelli, 2003; Schaap et al., 2001). Point pedotransfer methods used in this work were selected according to a previous study in a neighbouring basin (Zimmermann and Basile, 2008).

\subsection{Land use}

Extensive agriculture has taken place in the CRLB since the 1970s. Currently (2016), almost all of the study area (99\%) is dominated by industrial-scale agriculture producing primarily soybeans, corn and wheat. In this work, these three crops were assigned to "agricultural land" in land-use mapping and their planted areas were defined based on remote-sensing analysis, field collected data, and available information from local crop acreage databases.

According to the annual report submitted by producers regarding all cropland use on their farms (GSF, 2014), soybean and corn planted area are approximately $60 \%$ and $10 \%$, respectively. Wheat planted areas have been appreciably reduced for the period 2008-14 because soybean mono-cropping system has replaced the soybean/wheat rotation (i.e., soybean cultivars from early maturity group - April in the northern hemisphere and September in the southern hemisphere - are planted instead of late maturity group - June in the northern hemisphere, November in the southern hemisphere). As a consequence of the change in soybean planting date, the wheat growing area was approximately $12 \%$ until 2007 and decreased to almost 6\% for the period 2008-14.

Analysis of remote-sensing data in the 2013-14 growing season compensates for the inaccuracies in local crop acreage data in order to obtain more accurate land-use/land-cover mapping data. Cloud free Landsat satellite images 
acquired at different times during the growing season of each crop (December 22, 2013; January 23, March 12, July 18, August 19, September 20, October 22 and November 23, 2014) were downloaded from USGS EROS (USGS, 2015) and processed with Idrisi Selva software. Atmospheric effects were removed prior to data segmentation and classification operations based on the image-based COST model (Chavez, 1996). Field surveys, required for calibration and validation of remote-sensing analysis, were carried out in January 2014 (soybeans) and August 2014 (wheat). Fifty sites were surveyed for each crop throughout the study area. Data from 35 sites were used to generate spectral signatures from satellite imagery, and data from 15 sites were used to validate the quality of image classification. Supervised classifications based on the maximum likelihood classifier (Richards, 1986) indicated that remote-sensing data from December 2013 and September 2014 resulted in more accurate soybean and wheat acreage estimates, respectively. According to these more accurate estimates, wheat and soybean acreage in the 2013-14 season constituted approximately $20 \%$ and $70 \%$ of the study area, respectively. The corn planted area was evaluated by subtracting the soybean area $(70 \%)$ from the arable area obtained through NDVI classification, approximately $15 \%$. These results obtained through remote-sensing analyses are larger than the values reported by producers during the same growing season (6\% wheat, $10 \%$ corn and $60 \%$ soybeans). Therefore and because of the lack of surveyed sites for assessing the accuracy of older images classification, the local crop acreage data were rectified by increasing these values with the same percentage obtained during the 2013-14 season. As a result of this land-use classification, soybean and corn planted areas for SWAT simulation correspond to $70 \%$ and $15 \%$ of the numerical domain, respectively. While the wheat planted area is $40 \%$ up to 2007 and decreases to $20 \%$ from 2008 to the end of the simulation period.

Agricultural practices for each crop simulated with the SWAT model were derived through consultation with local farmers. Based on these consultations, representative SWAT operation schedules (e.g., planting and harvest dates, nutrient applications, and others) were defined for each crop type. Mineral fer- 
tilizers were applied at the time of planting at a rate of $14.14 \mathrm{~kg} \mathrm{P} / \mathrm{ha}$ and $67.8 \mathrm{~kg} \mathrm{~N} /$ ha for corn, $12.12 \mathrm{~kg} \mathrm{P} / \mathrm{ha}$ and $56.8 \mathrm{~kg} \mathrm{~N} /$ ha for wheat and $6.6 \mathrm{~kg}$ $\mathrm{P} /$ ha for soybeans (these values correspond to the average of collected data). The dominant crop cover simulated in the model included soybeans/wheat and corn/wheat rotations, as well as continuous soybeans.

\subsection{Streamflow}

The available streamflow information of Carcarañá River Basin is limited. Currently (2016), there are two active streamflow-gauging stations in the entire basin. This result represents one streamflow-gauging station per 25,000 km² This results in a low-density network compared to contributing drainage area of $500 \mathrm{~km}^{2}$ per station as per the average in the United States (Tsonis and Elsner, 2007). Only one of these two stations is situated in the CRLB (Pueblo Andino station - 32 40'24"S 6051'57.4" W, PA in Figure 1, operated by SSRH). The available data from these stations are water surface elevation, average daily flow discharge, and average monthly flow discharge.

In order to obtain a better distribution of streamflow information over the study area, field measurement surveys have been performed since 2013 on a seasonal basis. These surveys have been performed as a joint effort between Center for Studies in Water Technology of Córdoba National University; Secretary for Water Resources within the Ministry of Water and Environment of Córdoba Province and French Argentine International Center for Information and Systems Sciences. Three monitoring sites were added in the CRLB to provide flow characteristics data (stations R15, CA and PG in Figure 1). These data include bathymetry, water depths, velocities, discharges, and preliminary analyses of the main tributary contributions in the study area. Measuring discharges for various flow conditions (low, normal and high flows) allowed for the preparation of preliminary rating curves at the newly added monitoring sites. Monthly water-quality samplings were performed concurrently in order to quantify various constituent loads in the river flow from observed constituent concentration values (section 3.7). 


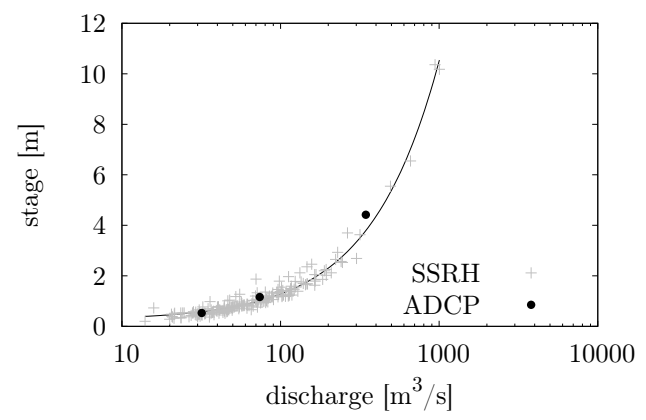

Figure 3: Stage-discharge curve at Pueblo Andino station during 1983-2014. Historical data collected by SSRH are shown with the ADCP measurements.

An Acoustic Doppler Current Profiler (ADCP) "River Surveyor S5 YSI / Sontek" has been used here for flow discharge measurements. This ADCP samples flow in a water-level range from $0.3 \mathrm{~m}$ to $15 \mathrm{~m}$ and provides section bathymetry (depth) and flow velocities in three orthogonal directions allowing flow discharge definition with a measurement error of less than $\pm 5 \%$. As the ADCP cannot move independently, the instrument needs to be fit on a floating platform to enable it to move across the river transect, keeping the correct speed and direction to achieve good quality measurements. Additional devices installed on the platform include a processing and communication module (using the Bluetooth system) and a differential GPS with its antenna. An even number of crossings or transects (four transects were performed in this work), with a minimum measurement time of 720 seconds at each gauging section, and a platform speed lower than the cross flow velocity ensured an accurate flow measurement (Mueller and Wagner, 2009).

Figure 3 shows the stage-discharge curve at the PA station used for estimating instantaneous discharges. ADCP measurements performed on October 1, 2013 (low discharge $\approx 30 \mathrm{~m}^{3} / \mathrm{s}$ ), November 19, 2013 (medium discharge $\approx 80 \mathrm{~m}^{3} / \mathrm{s}$ ) and April 9, 2014 (high discharge $\approx 350 \mathrm{~m}^{3} / \mathrm{s}$ ) together with historical records from SSRH are included in this graphic.

The inlet flow required by SWAT at R15 section (Fig. 1) was estimated based 
on precipitation data from CFSR and observed streamflow at the PA station. A monthly water balance between precipitation and streamflow was applied. Soil storage, percolation and evapotranspiration effects were taken into account using a runoff coefficient, $\mathcal{C}$. In this way, the monthly inlet flow at R15 section, $Q_{i n}$, was estimated as:

$$
Q_{\text {in }}=Q_{\text {out }}-\mathcal{C} \frac{P \Omega}{86400},
$$

where $Q_{\text {out }}$ is the observed monthly outlet flow at PA station, $P$ is the monthly precipitation and $\Omega$ is the subbasin area between R15 section and the PA station. Runoff coefficients were estimated according to Bertoni and Ganancias (2010). They studied the ratio between annual streamflow volume and annual precipitation in a subbasin (approximately $600 \mathrm{~km}^{2}$ ) of the Ctalamochita River, the major tributary of the Carcarañá River, during 1993-2002. Based on the linear equation provided by Bertoni and Ganancias, $\mathcal{C}=0.0002 \sum_{i=1}^{12} P+0.205$, runoff coefficient values, which ranged from 0.25 (dry years) to 0.45 (wet years), were evaluated.

\subsection{Water quality}

Water quality of streams and aquifers in agricultural areas can be affected by synthetic fertilizers, manure, and pesticide applications. Little water-quality information is available in the studied area. Because of lack of water-quality data, periodic field surveys have been performed since 2013. In these surveys, water samples are collected at monitoring sites (R15, CA, PA and PG in Figure 1), preserved and transported to a laboratory (Bone Biology Laboratory, Faculty of Medical Sciences, Rosario National University) to be processed according to recommendations by Rice et al. (2012).

The CRLB simulation period (1993-2013) encompasses only three waterquality surveys from 2013 (October 1, November 19, and December 11) hindering calibration for $\mathrm{N}$ and $\mathrm{P}$ concentration in streamflow. These streamflow concentrations still were considered to provide insight for SWAT water-quality simulations. Thus, an attempt was made to define $\mathrm{N}$ and $\mathrm{P}$ streamflow concen- 
tration data over a specific hydrologic period that correlates the concentration of specific grab water-quality samples to monthly average values.

It is often the case in agriculture-dominated hydrologic systems that a strong relation is present between streamflow and constituent concentration; therefore, using linear regression to estimate load from continuous flow and intermittent concentration data can be highly effective (Meals et al., 2013). In this work, a single regression relation is developed between concentration and streamflow based on days where constituent concentration data are available. Average daily streamflow at the PA station is available for the period from October through December in both 2013 and 2014. Instantaneous constituent concentrations from single grab samples have been obtained for these periods. A linear association between average daily streamflow and N/P concentration over these periods is established. The resulting equation is used to estimate N/P concentrations for each day on which a sample was not taken based on average daily streamflow values. Daily loads are obtained by multiplying the measured or estimated constituent concentration times the average daily streamflow. A bias correction factor is included in the calculation, to compensate for correlation effects among streamflow, load, and instantaneous concentration. This same correction factor is applied to the R15 section in order to obtain the average daily nitrate/phosphorus loading for the month as the required input for the SWAT model.

\subsection{Nitrogen use efficiency}

Nutrient use efficiency, and particularly nitrogen use efficiency (NUE) are critically important concepts in the evaluation of crop-production systems. Also, $\mathrm{N}$ balance provides information about the absolute nitrogen flow that is not captured in agricultural products and, therefore, potentially available for losses. NUE and $\mathrm{N}$ balance are different agro-environmental indicators. These two indicators can be combined into a system balance allowing quantification of all relevant $\mathrm{N}$ fluxes. The use of the SWAT model to simulate spatial and temporal $\mathrm{N}$ concentration in soil, plant, and water can add valuable information 
for choosing land-use practices, and optimal fertilizer application rates. In this work $11 \mathrm{~N} / \mathrm{P}$ fertilizer rates $(0,20,40,60,80,100,120,140,160,180$, and $200 \%$ ) are selected to simulate the effect of $\mathrm{N}$ fertilizer on yield, plant uptake, leaching, and constituent concentration in a river reach resulting from surface runoff. The "100\%" scenario corresponds to current farming practices in the study area, and it is considered as a baseline rate. N/P rates for different crops for current practices are described in Section 3.5.

Three basic issues must be addressed for NUE assessment: (a) how much of the applied $\mathrm{N}$ is taken up by crops, (b) how much additional crop yield is obtained for each additional unit of $\mathrm{N}$ uptake, and (c) how much of applied $\mathrm{N}$ was recovered and taken up by crops. Different indices can be used to assess NUE. In this work the following were consider: (i) partial factor productivity ( $\mathrm{PFP}=$ yield with nutrient applied/amount of nutrient applied) and (ii) agronomic efficiency ( $\mathrm{AE}=$ (yield with nutrient applied - yield with no nutrient applied)/amount of nutrient applied), related with production efficiency, where the output is the harvested crop; (iii) apparent crop-recovery efficiency of applied nutrient $(\mathrm{RE}=$ (total nutrient uptake with nutrient applied - nutrient uptake with no nutrient applied)/amount of nutrient applied), related to nutrient recovered by crops; (iv) internal utilization efficiency (IE=yield with nutrient applied/total nutrient uptake with nutrient applied) and (v) physiological efficiency $(\mathrm{PE}=$ (yield with nutrient applied - yield with no nutrient applied)/(total nutrient uptake with nutrient applied - nutrient uptake with no nutrient applied)), both related to the capacity of the crop to transform nutrient into economic yield. For definitions of these indices, along with their applications and limitations, see Fixen et al. (2015). Examples of these five NUE indices used to assess comparative effectiveness of fertilizer application rates and timing application or as agro environmental indicators can be found in Copperi et al. (2013), Dobermann (2007), García et al. (2013), Martinez et al. (2015) and Velasco et al. (2012). 


\subsection{Model calibration and validation.}

SWAT has been widely used for hydrological assessments. For other applications, such as to evaluate agricultural best-management practices, calibration/validation for in-stream water and nutrient fluxes may not be a valid approach if intra-watershed processes are not simulated with the appropriate sets of model parameters. Matching simulated and observed in-stream fluxes are a necessary, but not sufficient criteria for testing watershed models (White et al., 2012). In this work, basic procedures for automatic calibration are modified by considering a manual and automated combined calibration, where successive iteration steps incorporate information about intra-watershed processes in the parameter estimation. Intra-watershed responses (i.e., system processes and fluxes that result in spatial areas between streams and in upland portions of the watershed) usually are neglected because of limited monitoring data (Yen, 2012). The importance of using information about intra-watershed processes to produce accurate and useful model results that can be used in scenario testing and the effect of soft data on model calibration can be found in Arnold et al. (2015) and Yen et al. (2014), respectively. The combined manual and automated calibration/validation process incorporating sensitivity and uncertainty analysis is carried out in two stages. In the first stage, the one-at a -time (OAT) analysis is performed in order to identify a set of sensitive parameters and their range of sensitivity. In the second stage, the SUFI2 uncertainty analysis routine (Abbaspour et al., 2004, 2007) incorporated in SWAT-CUP tool (Abbaspour, 2015) is used for hydrology, nutrients, and crop yield calibration. OAT results obtained during the first stage serve as input data for SUFI2 calibration and validation scheme.

One-at a-time. OAT model analysis consists in modifying one input parameter at a time while others are kept at their nominal or baseline values. Therefore, each OAT change can be referenced to a certain model base space. Twenty-five input SWAT parameters related to hydrology, nutrients, and crop-yield processes were selected based on literature review from basins with similar char- 
acteristics to CLRB (Arnold et al., 2012b; Cibin et al., 2010; Douglas-Mankin et al., 2010; Havrylenko et al., 2016; Jha, 2009; Krysanova and White, 2015; Kumar et al., 2011; Schmalz and Fohrer, 2009; Tuppad et al., 2011). Because soybeans are widely cultivated in the studied area, only plant parameters of this species were included at this stage. Corn and wheat plant parameters are still incorporated in SUFI2 calibration and validation scheme.

Range interval was defined for each parameter based on available catchment data, such as soil maps and the methodology cited in section 3.4, for saturated hydraulic conductivity (SOL_K) and available water capacity (SOL_AWC). Observed streamflow at the PA station was considered for estimating the range for base-flow recession constant (ALPHA_BF), using a base-flow automated digital filter technique described in Arnold and Allen (1999) and Arnold et al. (1995). Knowledge gained in other studies and consultation with local citizens and stakeholders defined the groundwater delay time range $(3<$ GW_DELAY $<7$ days). Plant related parameter ranges were defined based on a synthesis of ranges from similar studies, within a physically meaningful range. The remainder of all 25 parameters were set to SWAT default ranges.

To generate a set of nominal values a preliminary single iteration of SUFI2 with 500 simulations is run, assuming the parameter range intervals described above. The simulation that best fits the average monthly streamflow is chosen as nominal values.

To quantify parameter sensitivity through the OAT analysis, five output variables were selected: average monthly streamflow out of reach (FLOW_out), recharge entering aquifers during the month (GW_RCHG), nitrate transported with water out of reach during the month (NO3_out), mineral phosphorus transported with water out of reach during the month (MINP_out) and average soybean annual yield (YLD). OAT analysis was applied by varying each parameter among 200 equidistant values within the ranges described above, and running SWAT for every parameter. Therefore, 200 different values of 5 screened output variables were obtained. An L2 difference norm $\|\Delta x(j)\|_{2}$, is computed for subsequent output variable values as follows 


$$
\|\Delta x(j)\|_{2}=\sqrt{\frac{\sum_{i=1}^{192}\left(x_{i, j+1}-x_{i, j}\right)^{2}}{192}}, j=[1, \ldots, n s-1],
$$

where $x$ represents the output variable, $i$ the number of the simulated month (i.e., 16 years, where the first 5 years are used as a warming up period, and, therefore, discarded) and $j$ the number of the tested parameter range subdivision or steps of the process $(n s=200)$.

Results of Eq. 1 for every parameter are plotted in a 2-dimensional data sequence line plot. An initial range interval for running SUFI2 is assessed graphically from these plots. Sensitive parameters for each output variable are then ranked from high to low on the basis of the ratio between $\|\Delta x(j)\|_{2} \max _{k} / \max \left(\|\Delta x(j)\|_{2} \max _{k}\right)$ $(j=[1: 199] ; k=[1: 25])$, using a value of 0.01 as threshold, above which parameters are deemed "sensitive" for the considered output variable. These sensitive parameters are the parameters that are considered for calibration. Further details on OAT analysis are given in section 4.1.

SUFI2. OAT sensitivity analysis provides important insight into the varying dependency of parameter sensitivity on hydrologic, water-quality and crop yield conditions. This analysis allows for the definition of sensitive parameters ranking and initial parameter ranges per output variable, making this the starting point of a semi-automated calibration process. The SUFI2 procedure, an algorithm implemented in SWAT-CUP software package, was undertaken based on OAT results. In SUFI2, uncertainty in parameters, expressed as ranges (uniform distributions), accounts for all sources of uncertainties such as uncertainty in driving variables (e.g., rainfall), conceptual model, parameters, and measured data. Propagation of parameter uncertanties lead to uncertainties in the model output variables, which are expressed as the $95 \%$ probability distributions. These variables are calculated at the $2.5 \%$ and $97.5 \%$ levels of the cumulative distribution of an output variable generated by propagation of the parameter uncertainties using Latin hypercube sampling. This result is referred to as the $95 \%$ prediction uncertainty, or 95PPU. These 95PPUs are the model 
outputs in a stochastic calibration approach (Abbaspour, 2015).

The quality of the fit between simulation result (95PPU) and observation (expressed as a single signal) is characterized by two statistics: p-factor and rfactor. P-factor is the percentage of observed data encompassed by the modeling results. R-factor is the $95 \mathrm{PPU}$ envelope thickness. A value of $\mathrm{p}$-factor greater than $70 \%$ for discharge is suggested along with an r-factor of approximately 1 . More information concerning SUFI2 uncertainty analysis routine can be found in Abbaspour (2015).

Average monthly streamflow time series recorded at the PA station during 1993-2008 were used for calibration (i.e., 11 years with the first 5 years used as a warming up period).

Average annual soybean, corn, and wheat yield were also calibrated for 19932008. Information of agricultural production was provided by the Ministry of Agriculture, Livestock and Fisheries (Ministerio de Agricultura, Ganadería y Pesca de la Nación Argentina/MAGyP).

Groundwater recharge calibration is based on results reported by Venencio (2008). Venencio quantified seasonal groundwater recharge using a daily waterbalance model for 2000-03 based on four precipitation and water-table stations (La Silesia, Oliveros, San Jorge and Andino). Seasonal ratio of groundwater recharge to precipitation at the La Silesia station were considered in this work for CRLB calibration. The other three stations were discarded because of a low correspondence between their precipitation data sets and available rainfall in CRLB.

For model validation, an iteration was run keeping the calibrated parameter ranges with the same number of simulations as used for calibration. The validation process was performed from 2009 to 2013. Only streamflow and yield are validated because there are no data available for groundwater recharge in other periods. 


\section{Results}

In this section a thorough description of the calibration and validation process, along with SWAT results are first presented. Second, different agricultural scenarios corresponding to different fertilizer application amounts are simulated and analysed.

\subsection{Calibration and validation}

OAT. The results of OAT model-sensitivity analysis are summarized in Figure 4 and Table 1. L2 difference norm values (Eq. 1) for subsequent subdivisions of the considered input parameter range are shown in Figure 4. The output variable analysed in this figure is the average monthly streamflow out of the reach, i.e. FLOW_out. Subplots (a) to (d) correspond to variations of SURLAG, CN2, ESCO and EPCO, respectively. The same procedure is followed for the 25 input parameters selected, and these parameters are ranked according to maximum difference norm values.

The 25 input parameters, the maximum difference norm per parameter $\left(\|\Delta x\|_{2} \max \right)$, and the ratio between the maximum difference norm per parameter over the absolute maximum difference norm per output variable are given in Table 1. In this case, the output variable is FLOW_out and the absolute maximum L2 difference norm, $\max \left(\|\Delta x\|_{2} \max \right)$, equals 10.97 . Only 8 of the 25 parameters will be taken into consideration for calibration and validation SUFI2 scheme.

Once the ranking is defined, the sensitivity range for each parameter is graphically accounted, selecting the interval where the difference norm plot presents higher gradients. Therefore, the identified ranges (Fig. 4) are: $0<$ SURLAG $<10$ (Fig. 4a), $60<\mathrm{CN} 2<98$ (Fig. 4b), $0.3<\mathrm{ESCO}<1.0$ (Fig. 4c) and $0<\mathrm{EPCO}<0.6$ (Fig. 4d). Ranges for the remaining four parameters are 0 $<$ GWQMN $<1000,-0.25<$ SOL_AWC $<0.25,15<$ T_OPT $<30$ and $8<$ T_BASE $<12$. Up to this time in this work, OAT analysis was performed only for FLOW_out output variable. The same procedure is carried out for 


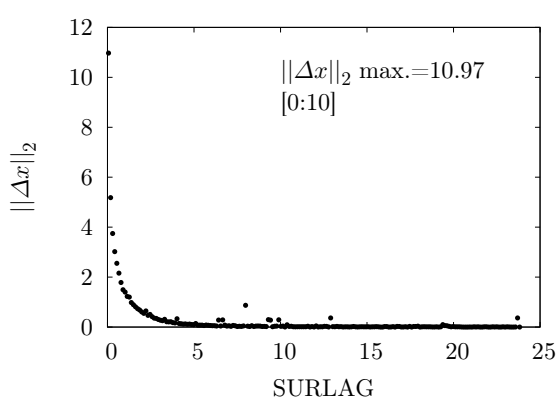

(a)

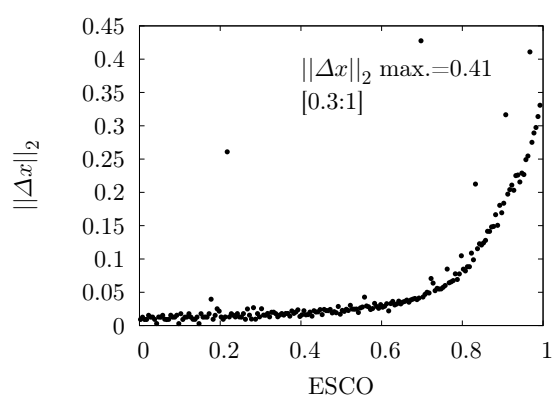

(c)

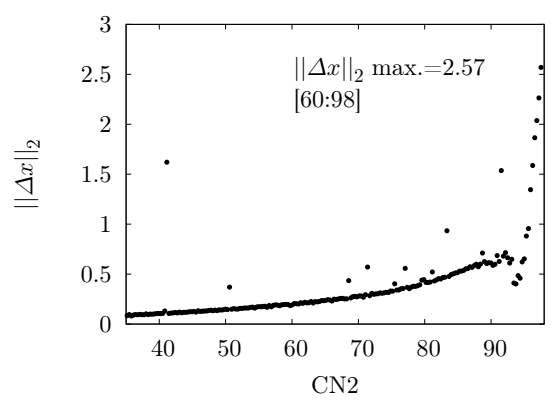

(b)

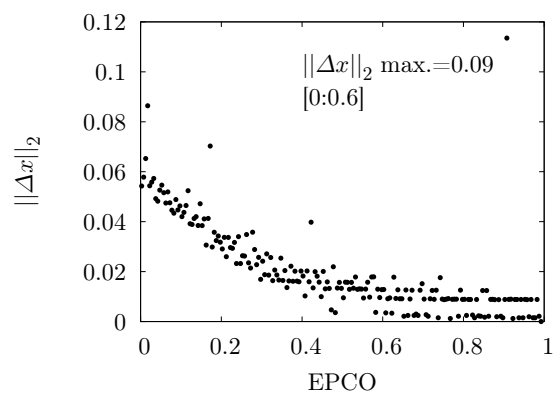

(d)

Figure 4: Sensitivity of the streamflow output variable FLOW_out to the input parameters SURLAG, CN2, ESCO and EPCO. 
Table 1: OAT ranking of selected input SWAT parameters for FLOW_out output variable.

\begin{tabular}{|c|c|c|}
\hline Parameter & $\|\Delta x\|_{2} \max$ & $\|\Delta x\|_{2} \max / \max \left(\|\Delta x\|_{2} \max \right)^{*}$ \\
\hline v_SURLAG.bsn** & 10.97 & 1.00 \\
\hline r_CN2.mgt*** & 2.57 & 0.23 \\
\hline v_GWQMN.gw & 2.39 & 0.22 \\
\hline r_SOL_AWC().sol & 0.92 & 0.08 \\
\hline v_T_OPT(56).plant.dat & 0.58 & 0.05 \\
\hline v_ESCO.hru & 0.41 & 0.04 \\
\hline v_T_BASE(56).plant.dat & 0.13 & 0.01 \\
\hline v_EPCO.hru & 0.09 & 0.01 \\
\hline v_ALPHA_BF.gw & 0.05 & 0.00 \\
\hline r_SOL_K().sol & 0.05 & 0.00 \\
\hline r_OV_N.hru & 0.04 & 0.00 \\
\hline v_GW_REVAP.gw & 0.021 & 0.00 \\
\hline v_EXT_COEF(56).plant.dat & 0.016 & 0.00 \\
\hline v_N_UPDIS.bsn & 0.014 & 0.00 \\
\hline v_BIO_E(56).plant.dat & 0.012 & 0.00 \\
\hline v_HVSTI(56).plant.dat & 0.01 & 0.00 \\
\hline v_NPERCO.bsn & 0.09 & 0.00 \\
\hline v_ERORGN.hru & 0.08 & 0.00 \\
\hline v_REVAPMN.gw & 0.00 & 0.00 \\
\hline v_GW_DELAY.gw & 0.00 & 0.00 \\
\hline v_PPERCO.bsn & 0.00 & 0.00 \\
\hline v_P_UPDIS.bsn & 0.00 & 0.00 \\
\hline v_PHOSKD.bsn & 0.00 & 0.00 \\
\hline v_PSP.bsn & 0.00 & 0.00 \\
\hline v_ERORGP.hru & 0.00 & 0.00 \\
\hline
\end{tabular}

${ }^{*} \max \left(\|\Delta x\|_{2} \max \right)=10.97$

${ }^{* *}{ }^{*}$ - means the existing parameter value is to be replaced by a given value.

${ }^{* * *}{ }^{2}{ }_{-}$means an existing parameter value is multiplied by (1+ a given value). 
Table 2: OAT sensitivity of selected input SWAT parameters.

\begin{tabular}{|c|c|c|c|c|c|c|}
\hline \multirow{2}{*}{ Parameter } & \multicolumn{5}{|c|}{ Sensitivity } & \multirow{2}{*}{$\begin{array}{c}\text { Initial Range } \\
\text { SUFI2 }\end{array}$} \\
\hline & FLOW_out & GW_RCHG & YLD & NO3_out & MINP_out & \\
\hline r_CN2.mgt & $\mathrm{X}$ & $\mathrm{X}$ & $\mathrm{X}$ & $\mathrm{X}$ & $\mathrm{X}$ & $-0.21: 0.28$ \\
\hline v_SURLAG.bsn & $\mathrm{X}$ & & & $\mathrm{X}$ & $\mathrm{X}$ & $0: 10$ \\
\hline v_ESCO.hru & $\mathrm{X}$ & $\mathrm{X}$ & $\mathrm{X}$ & $\mathrm{X}$ & $\mathrm{X}$ & $0.3: 1$ \\
\hline r_OV_N.hru & & & & $\mathrm{X}$ & $\mathrm{X}$ & $-0.25: 0.25$ \\
\hline v_EPCO.hru & $\mathrm{X}$ & $\mathrm{X}$ & $\mathrm{X}$ & $\mathrm{X}$ & $\mathrm{X}$ & $0: 0.6$ \\
\hline v_N_UPDIS.bsn & & $\mathrm{X}$ & & & & $0: 30$ \\
\hline \multicolumn{7}{|l|}{ v_ERORGN.hru } \\
\hline v_NPERCO.bsn & & & & $\mathrm{X}$ & & $0: 1$ \\
\hline \multicolumn{7}{|l|}{ v_PSP.bsn } \\
\hline v_PHOSKD.bsn & & & & & $\mathrm{X}$ & $100: 185$ \\
\hline v_P_UPDIS.bsn & & & & & $\mathrm{X}$ & $0: 60$ \\
\hline v_ERORGP.hru & & & & & $\mathrm{X}$ & $0: 3$ \\
\hline \multicolumn{7}{|l|}{ v_PPERCO.bsn } \\
\hline v_ALPHA_BF.gw & & & & $\mathrm{X}$ & $\mathrm{X}$ & 0.018:0.03 \\
\hline v_GW_DELAY.gw & & $\mathrm{X}$ & & & & $3: 7$ \\
\hline v_GW_REVAP.gw & & & & $\mathrm{X}$ & & $0.02: 0.2$ \\
\hline v_GWQMN.gw & $\mathrm{X}$ & & & $\mathrm{X}$ & $\mathrm{X}$ & 0:1000 \\
\hline r_SOL_AWC().sol & $\mathrm{X}$ & $\mathrm{X}$ & $\mathrm{X}$ & $\mathrm{X}$ & $\mathrm{X}$ & $-0.25: 0.25$ \\
\hline r_SOL_K().sol & & $\mathrm{X}$ & & $\mathrm{X}$ & $\mathrm{X}$ & $-0.5: 0.3$ \\
\hline \multicolumn{7}{|l|}{ v_REVAPMN.gw } \\
\hline v_HVSTI(56).plant.dat & & & $\mathrm{X}$ & & & 0.3:0.6 \\
\hline v_T_BASE(56).plant.dat & $\mathrm{X}$ & & $\mathrm{X}$ & $\mathrm{X}$ & $\mathrm{X}$ & $8: 12$ \\
\hline v_EXT_COEF(56).plant.dat & & & $\mathrm{X}$ & & $\mathrm{X}$ & $0.3: 0.5$ \\
\hline v_BIO_E(56).plant.dat & & & $\mathrm{X}$ & & $\mathrm{X}$ & $20: 30$ \\
\hline v_T_OPT(56).plant.dat & $\mathrm{X}$ & & $\mathrm{X}$ & $\mathrm{X}$ & $\mathrm{X}$ & $15: 30$ \\
\hline
\end{tabular}


each of the five screened output variables. The OAT results are summarized in Table 2. The final parameter ranges (Table 2) result from the union of the ranges for each output variable (FLOW_out, GW_RCHG, NO3_out, MINP_out, and YLD). These narrower ranges (when compared to the previous range) will serve as SUFI2 input data improving the degree to which the calibrated model accounts for uncertainties and saving computational effort. Otherwise, OAT results show that input parameters related to hydrology, such as CN2, ESCO, EPCO and SOL_AWC are found at the top rank for all output analysed variables. Therefore, an efficient calibration is needed in order to keep the other output variables within a reliable range.

SUFI2. The calibration process involved five steps that are summarized in Table 3. Each step was undertaken to calibrate a different output variable. From the second step onwards, variables calibrated in previous steps are verified. Because model performance highly depends on the hydrology of the basin, the first calibrated output variables are streamflow and groundwater recharge. The last variables used to calibrate the CRLB model are soybeans, corn, and wheat yield, in this order. In this work, the Nash-Sutcliff (NS) objective function was applied. Eight identified sensitive input parameters (listed in the second column of Table 2) were considered for streamflow calibration in the first step. Three iterations of 500 simulations each were performed to obtain satisfactory results for p-factor (0.78) and r-factor (0.31) (step 1 in Table 3). In the second step, groundwater recharge was calibrated. There are two types of recharge parameters, those that affect only recharge and those that affect streamflow and recharge (Table 2). Initially, three groundwater recharge parameters that only affect recharge were added (GW_DELAY, SOL_K, and N_UPDIS).

Given that quality of the fit after one iteration was not satisfactory (p-factor and $r$-factor values of 0.06 were obtained), four parameters that affect both, recharge and streamflow, were additionally allowed to change (CN2, ESCO, EPCO and SOL_AWC). After three iterations this second approach with seven sensitive parameters resulted in better recharge results. Attaining acceptable 
simulation of the recharge dynamics, with $\mathrm{p}$-factor $=0.30$ and $\mathrm{r}$-factor $=0.60$. In addition, when streamflow was verified for the new parameters range, a better fit resulted ( $\mathrm{p}$-factor $=0.98$ and $\mathrm{r}$-factor $=0.49$, step two in Table 3 ) than the former streamflow calibration $(\mathrm{p}$-factor $=0.78$ and $\mathrm{r}$-factor $=0.31$, step one in Table 3 ). According to p-factor values, the 95PPU in this second step covered $20 \%$ more of the observed data than was covered in the first step.

For soybean yield calibration (step three in Table 3), three parameters sensitive only to soybean production were added (HVSTI, EXT_COEF and BIO_E). After three iterations, with 500 simulations per iteration, a soybean yield calibration with p-factor and r-factor values of 0.55 and 5.90, respectively, were successfully obtained. Streamflow and groundwater recharge results did not present an appreciable change between the second and the third step. For corn and wheat production (steps four and five in Table 3), the same procedure applied for soybeans was repeated. Five corn and wheat plant parameters (HVSTI, EXT_COEF and BIO_E, T_BASE and T_OP) were added respectively.

At the end of the analysis, twenty four parameters were considered for streamflow, recharge, and yield calibration. The obtained results are summarized in step five (Table 3). Results shown below dashed lines (Table 3), for steps 2 to 5 , correspond to the verification process for parameter ranges obtained for those variables being calibrated. The overall quality of the fit is satisfactory considering the input data limitations. CRLB discharges are well simulated with $\mathrm{p}$-factor $=0.98, \mathrm{r}$-factor $=0.48$ and $\mathrm{NS}=0.91$. Calibrated yields show p-factor values in the range from 0.98 to 0.55 , r-factor values in the range from 0.48 to 5.74 , and NS values in the range from -4.96 to -0.57 . These results indicate that, on an average basis, soil moisture, groundwater recharge, and evapotranspiration are well simulated. The calibrated parameter ranges are listed in Table 4. Without modifying these ranges, an iteration with the same number of simulations used for calibration was run to perform validation during 2009-13. The quality of the validation fit expressed by p-factor, r-factor, NS efficiency, and percent bias (PBIAS) values are shown in Table 5.

The simulated results of average monthly streamflow, expressed by the 95PPU, 
Table 3: CRLB calibration processes. A calibrated step consists of 3 iterations with 500 simulations each. The calibration period for streamflow and soybean, corn, and wheat yield was 1993-2008; for groundwater recharge, the calibration period was 2000-03.

\begin{tabular}{|c|c|c|c|c|}
\hline Step & Objective & Parameters & p-factor & r-factor \\
\hline 1 & FLOW_out & 8 (8 FLOW_out) & 0.78 & 0.31 \\
\hline \multirow{3}{*}{2} & GW_RCHG & 11 (8 FLOW_out* +3 GW_RCHG) & 0.06 & 0.06 \\
\hline & GW_RCHG & 11 (4 FLOW_out* +7 GW_RCHG) & $\begin{array}{c}0.30 \\
----\end{array}$ & $\begin{array}{c}0.60 \\
-----\end{array}$ \\
\hline & verif. FLOW_out & $\begin{array}{c}11 \text { (4 FLOW_out* }+7 \\
\text { GW_RCHG* })\end{array}$ & 0.98 & 0.49 \\
\hline \multirow{4}{*}{3} & YIELD soyb. & 14 (4 FLOW_out* +7 & 0.55 & 5.9 \\
\hline & ----------- & GW_RCHG* +3 YIELD soyb.) & ----- & ----- \\
\hline & verif. FLOW_out & 14 (4 FLOW_out* +7 & 0.98 & 0.48 \\
\hline & verif. GW_RCHG & GW_RCHG* + 3 YIELD soyb.*) & 0.29 & 0.65 \\
\hline \multirow{6}{*}{4} & & 19 (4 FLOW_out* +7 & & \\
\hline & YIELD corn & GW_RCHG* +3 YIELD soyb. ${ }^{*}+$ & 0.73 & 3.32 \\
\hline & ------- & $\begin{array}{c}5 \text { YIELD corn) } \\
-\ldots-\ldots-\ldots\end{array}$ & -- & ----- \\
\hline & verif. FLOW_out & 19 (4 FLOW_out* +7 & 0.98 & 0.48 \\
\hline & verif. GW_RCHG & GW_RCHG ${ }^{*}+3$ YIELD soyb.* & 0.29 & 0.67 \\
\hline & verif. YIELD soyb. & + 5 YIELD corn*) & 0.55 & 5.50 \\
\hline \multirow{7}{*}{5} & & 24 (4 FLOW_out* +7 & & \\
\hline & YIELD wheat & GW_RCHG* +3 YIELD soyb. ${ }^{*}+$ & 0.91 & 2.15 \\
\hline & ---------- & 5 YIELD corn* +5 YIELD wheat) & -- & --- \\
\hline & verif. FLOW_out & 24 (4 FLOW_out ${ }^{*}+7$ & 0.98 & 0.48 \\
\hline & verif. GW_RCHG & GW_RCHG ${ }^{*}+3$ YIELD soyb.* & 0.29 & 0.64 \\
\hline & verif. YIELD soyb. & +5 YIELD corn* ${ }^{*}+5$ YIELD & 0.55 & 5.74 \\
\hline & verif. YIELD corn & wheat*) & 0.73 & 3.46 \\
\hline
\end{tabular}

${ }^{*}$ parameters ranges are fixed from the previous calibrated step. 
Table 4: Calibrated parameter ranges.

\begin{tabular}{cc}
\hline Parameter & Calibrated range \\
\hline v_SURLAG.bsn & $0.09: 4.20$ \\
v_GWQMN.gw & $559.32: 853.17$ \\
v_T_OPT(56).plant.dat & $24.09: 30.00$ \\
v_T_BASE(56).plant.dat & $10.57: 12.00$ \\
r_SOL_AWC().sol & $0.013: 0.21$ \\
r_CN2.mgt & $-0.065: 0.23$ \\
v_ESCO.hru & $0.80: 1$ \\
v_EPCO.hru & $0: 0.17$ \\
r_SOL_K().sol & $-0.06: 0.20$ \\
v_GW_DELAY.gw & $3: 4.62$ \\
v_N_UPDIS.bsn & $16.89: 28.75$ \\
v_EXT_COEF(56).plant.dat & $0.42: 0.5$ \\
v_BIO_E(56).plant.dat & $24.76: 28.14$ \\
v_HVSTI(56).plant.dat & $0.46: 0.55$ \\
v_T_OPT(19).plant.dat & $16.68: 28.82$ \\
v_T_BASE(19).plant.dat & $6.25: 7.81$ \\
v_EXT_COEF(19).plant.dat & $0.61: 0.73$ \\
v_BIO_E(19).plant.dat & $43.31: 50$ \\
v_HVSTI(19).plant.dat & $0.64: 0.7$ \\
v_T_OPT(28).plant.dat & $14.28: 22.09$ \\
v_T_BASE(28).plant.dat & $-0.86: 1.39$ \\
v_EXT_COEF(28).plant.dat & $0.61: 0.73$ \\
v_BIO_E(28).plant.dat & $33.20: 40$ \\
v_HVSTI(28).plant.dat & $0.3: 0.40$ \\
\hline & \\
\hline
\end{tabular}


Table 5: Quality of the CRLB validation expressed by p-factor, r-factor, NS and PBIAS values. Validation period 2009-13.

\begin{tabular}{cccccc}
\hline Objective & Parameters & p-factor & r-factor & NS & PBIAS \\
\hline FLOW_out & $24\left(4\right.$ FLOW_out $^{*}+7$ & 0.80 & 0.33 & 0.94 & -5.50 \\
YIELD soyb. & GW_RCHG* +3 YIELD soyb. & 0.40 & 3.21 & -11.28 & 24.40 \\
YIELD corn & +5 YIELD corn* +5 YIELD & 0.20 & 2.50 & -1.53 & 10.30 \\
YIELD wheat & wheat $\left.^{*}\right)$ & 0.60 & 1.27 & -0.11 & 5.20 \\
${ }^{*}$ calibrated parameter ranges. & & & & &
\end{tabular}

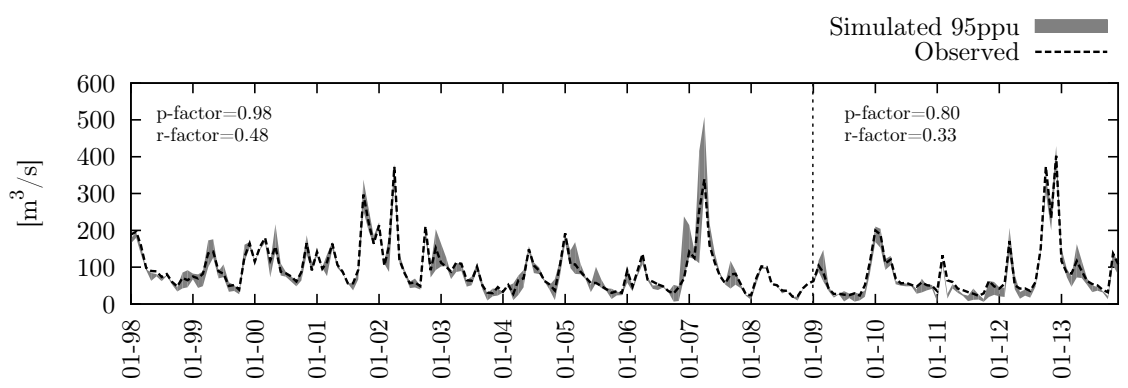

Figure 5: Observed and simulated average monthly streamflow at the PA station. Calibration period 1993-2008, validation period 2009-13.

and the observed time series for calibration/validation period at the PA station are shown in Figure 5. Simulation results are satisfactory, as 95PPU covers $98 \%$ of observed data in calibration period with $48 \%$ of relative width. The validation period slightly reduces the fit quality, simulated results encompasses $80 \%$ of observed average monthly streamflow with a smaller relative width of $33 \%$.

The simulated 95PPU results of amount of water entering the aquifer during the month are shown in Figure 6. Calibration was based on the seasonal ratio of groundwater recharge to precipitation at the La Silesia station during 2000-03 given by Venencio (2008). As shown in terms of p-factor, almost $30 \%$ of the simulated results follow the reported values. Still, a large discrepancy between 


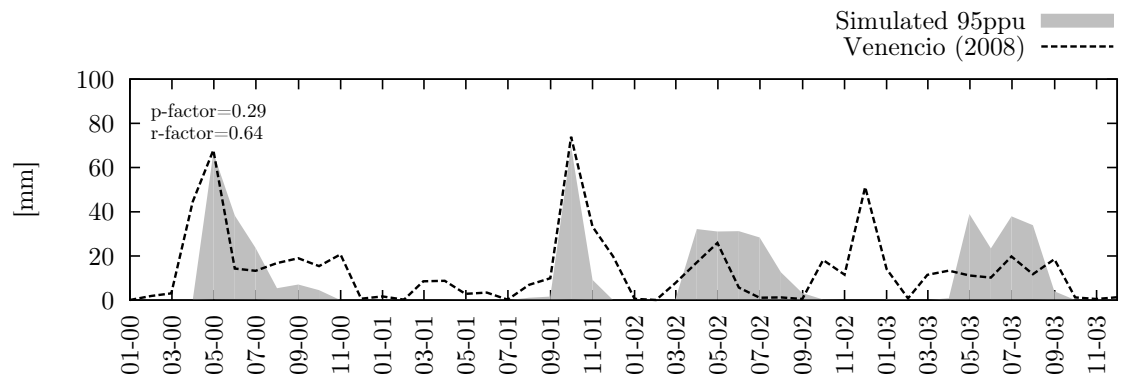

Figure 6: Observed and simulated monthly recharge entering aquifers during 2000-03.

simulated recharge and that evaluated from Venencio (2008) is seen for December 2002. This issue might be explained as an effect of accumulated precipitation for antecedent dry periods (April-November). The relation between antecedent rainfall and groundwater recharge is difficult to quantify, particularly because of the inherent unpredictability and natural variability in rainfall. Both series of precipitation data (La Silesia station and CFSR data) for 2000, 2001, and 2003 match well. However, this is not the case for 2002, where Venencio's accumulated rainfall for April-November is twice the value of accumulated rainfall used for simulation (i.e., La Silesia data $827.33 \mathrm{~mm}$ and CFSR data $413.7 \mathrm{~mm}$ ).

Average annual yield results of the main agricultural commodities, such as soybeans, corn, and wheat, can be seen in Figure 7. Overall, the SWAT model was able to simulate crop yields for corn and wheat reasonably accurately. Calibration improved the model performance for corn and wheat but not for soybeans. Simulated results of average annual soybean yield along with data reported by MAGyP for CRLB region are shown in Figure 7a. Numerical simulations better reflect MAGyP data in the triennial from 2001-02 to 2003-04 and single 2009-10 crop years. In contrast, high variability of annual soybean production can be seen for the entire simulated period, not representing soybean vegetative plasticity. Possibly, these results are affected by both dry months over the growing period and the simulated climatic conditions. More effort must be applied to use site-specific soybean calibration parameters to 

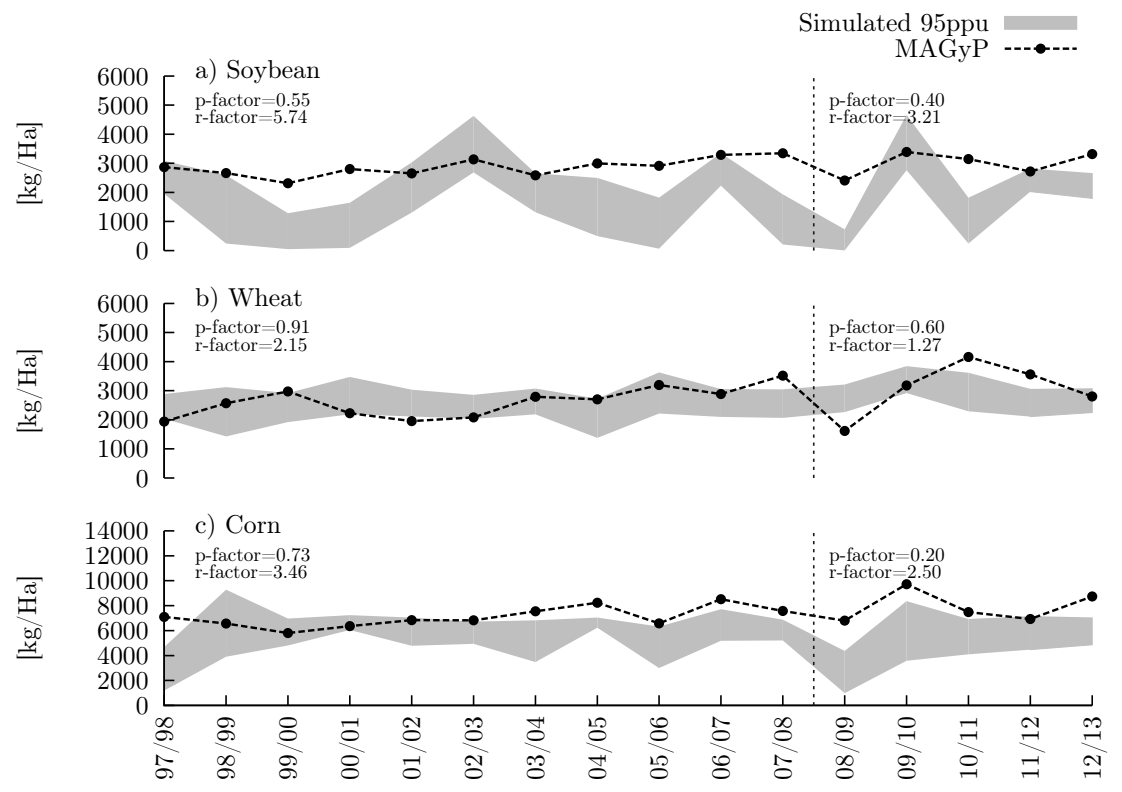

Figure 7: Simulated average annual crop yield and data reported by MAGyP. Calibration period 1993-2008, validation period 2009-13. (a) Soybean, (b) Wheat and (c) Corn, respectively.

minimize the effects of model performance.

Wheat yield results can be seen in Figure 7b. Simulated average annual wheat yield mostly follows the observed data reported by MAGyP for CRLB. There is a good match in the calibration period where $91 \%$ of the simulated results covered the reported data. Validation quality slightly decreases, although $60 \%$ of numerical results covered the MAGyP data.

The simulated and reported data of average annual corn yield in CRLB is shown in Figure 7c. Numerical results, expressed by the 95PPU, agree with MAGyP data covering $73 \%$ of the observations during calibration period. The fit quality decreases during validation period, where $20 \%$ of reported data are covered by model-simulation results.

Nitrate and phosphorus. The simulated results of N/P concentration (i.e., the ratio between the average monthly load and the average monthly streamflow) 

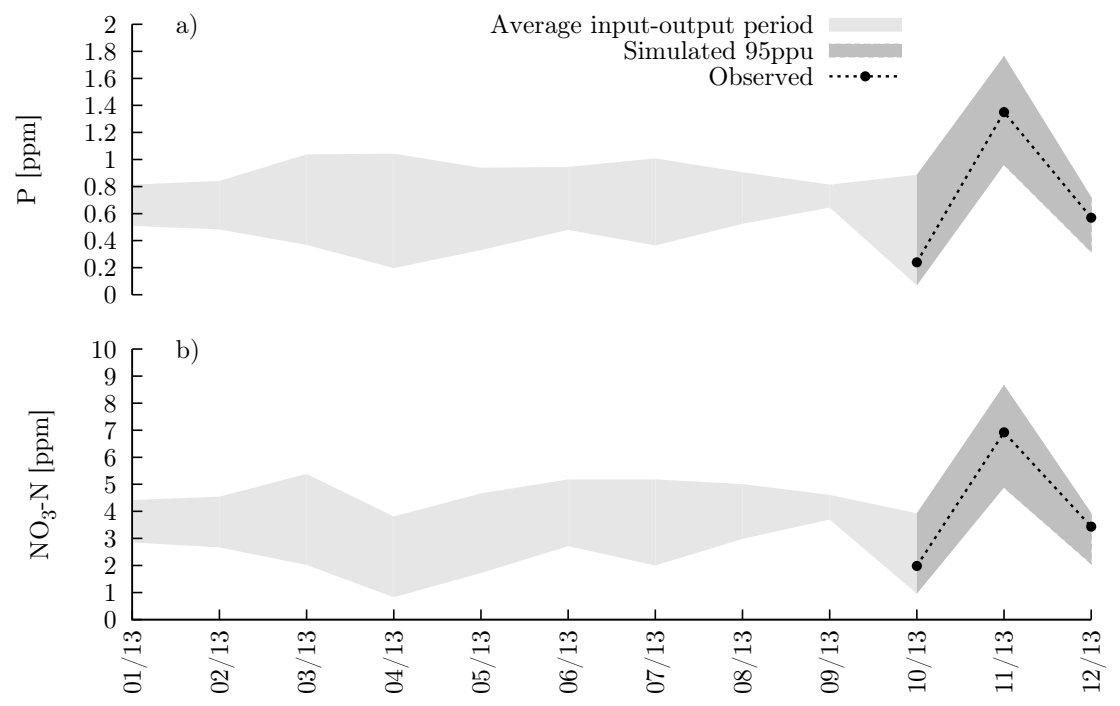

Figure 8: Phosphorus and nitrogen concentration (i.e., the ratio between the average monthly load and the average monthly streamflow) at the PA station in 2013. a) Phosphorus and b) Nitrate Nitrogen $\mathrm{NO}_{3}-\mathrm{N}$.

at the PA station in 2013 along with the corrected instantaneous concentration, as explained in Section 3.7, is shown in Figure 8. Simulated results of N/P concentrations for the January-September 2013 period are plotted in light grey. The corresponding input values at the R15 station were the average N/P loads for October-November-December 2013. The model was run for different N/P input values, and no effect was observed on simulated results for those months in which grab samples are available.

\subsection{Different nitrogen fertilization rates. Simulation and analysis.}

This section describes the assessment of soil and water resources in regions with limited data by performing a preliminary scenario analysis, where different fertilizer rates are applied. Results for NUE are shown for corn and wheat because no additional $\mathrm{N}$ is needed for soybean production. 
PFP specifies how much yield is produced per unit of applied N. Simulated results for PFP vs $\mathrm{N}$ rate are shown for corn and wheat in Figure 9a. The ranges of variation are in good agreement with experimental results reported in the literature. In García et al. (2013), experimental results for PFP for wheat vary from 40 to 100, in Argentina during 1998-2012. Numerical results span these values of PFP for $\mathrm{N}$ rates varying from $40 \%$ to $140 \%$ (see Figure 9a). For the same period, experimental PFP results for corn vary between 60 and 200, whereas numerical results cover these values for the entire range of $\mathrm{N}$ rates considered. PFP values for corn in Argentina, are greater than international reference values (40-80, Dobermann, 2007; Fixen et al., 2015), indicating that corn is taking up soil organic $\mathrm{N}$ fraction, and, therefore, degrading soil and water quality. In order to compare the results of this work with cited references, the absolute $\mathrm{N}$ application rates are included in Figure 9.

AE refers to the increase in crop yield per unit of applied N. Literature review of different studies, covering south of Santa Fe, centre of Córdoba and Buenos Aires provinces, provided results varying from 9 to 28 for wheat and from 13 to 71 for corn (García et al., 2013). Copperi et al. (2013) reported, for $\mathrm{N}$ rates below $85 \mathrm{~kg} /$ ha for corn fertilization, values for $\mathrm{AE}$ between 65 and 87 (depending on the type of fertilizer), values that span much the same range of values obtained in this work for corn simulation (Fig. 9b). Recent research on NUE for wheat, in a semiarid region of Buenos Aires province (Martinez et al., 2015), conducted fertilization trials for different $\mathrm{N}$ rates, i.e. 0, 25, 50, and $100 \mathrm{~kg} / \mathrm{ha}$. Experimental results for AE, for a 5-year period, obtained values ranging from 13 to 46 ; thus, these values are in good agreement with simulated AE results (Fig. 9b).

$\mathrm{RE}$ addresses how much of the $\mathrm{N}$ applied is recovered and taken up by crops. $\mathrm{RE}$ represents the potential for $\mathrm{N}$ loss from the cropping system, and assesses the efficiency of management practices. Copperi et al. (2013) reported values for RE for corn ranging between 1.14 and 1.34, whereas Martinez et al. (2015) estimated RE for wheat between 0.3 and 0.8. Simulated results for RE for corn and wheat are shown in Figure 9c, and accurately match experimental data. 


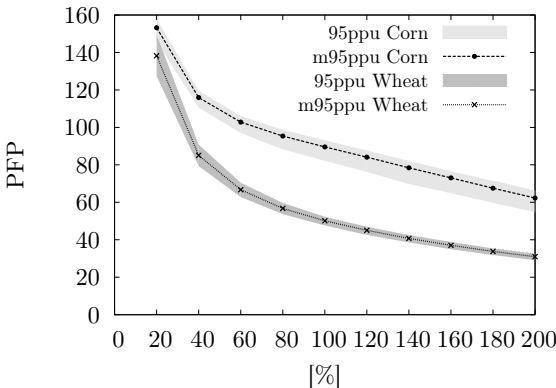

(a)

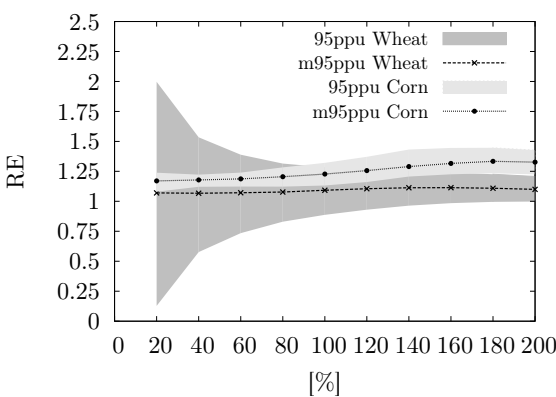

(c)

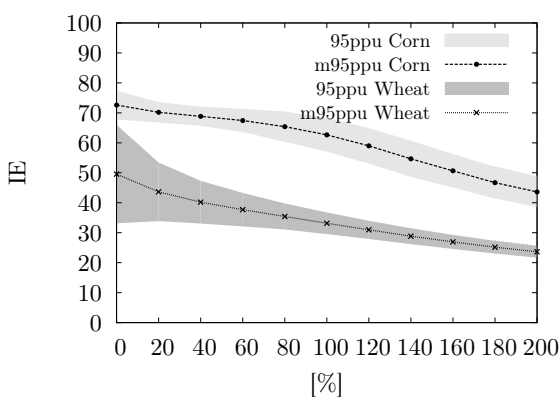

(e)

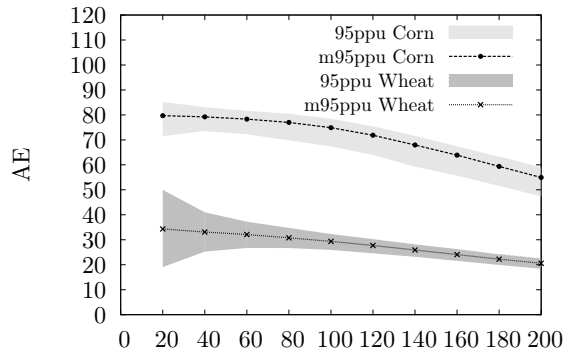

[\%]

(b)

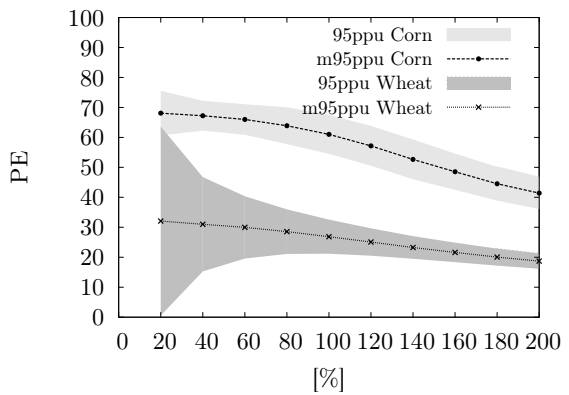

(d)

Figure 9: Average values of common indices to evaluate NUE in the period 1998-2013 vs different fertilizer application rates. (a) $\mathrm{PFP}=\mathrm{Y} / \mathrm{F}$, (b) $\mathrm{AE}=(\mathrm{Y}-\mathrm{Yo}) / \mathrm{F}$, (c) $\mathrm{RE}=(\mathrm{U}-\mathrm{Uo}) / \mathrm{F}$, (d) $\mathrm{PE}=(\mathrm{Y}-\mathrm{Yo}) /(\mathrm{U}-\mathrm{Uo})$ and $(\mathrm{e}) \mathrm{IE}=\mathrm{Y} / \mathrm{U}$. $\mathrm{Y}=$ yield with nutrient applied $[\mathrm{kg} / \mathrm{ha}] ; \mathrm{Yo}=$ yield with no nutrient applied $[\mathrm{kg} / \mathrm{ha}] ; \mathrm{F}=$ amount of nutrient applied $[\mathrm{kg} \mathrm{N} / \mathrm{ha}] ; \mathrm{U}=$ total nutrient uptake with nutrient applied [kg N/ha]; Uo = nutrient uptake with no nutrient applied $[\mathrm{kg}$ $\mathrm{N} / \mathrm{ha}$. 
The separation of AE into its RE and PE components usually provides the means to identify problems in fertilizer response experiments. PE characterizes the capability of converting a given amount of nutrient acquired from the source applied into economic yield. Simulated values of PE vs different fertilizer application rates are shown in Figure 9d. Numerical results of PE for wheat are in good agreement with experimental results obtained in Argentina (12-40, Velasco et al., 2012). Simulated PE values for corn, in the range of fertilizer application rates $0-100$, are greater than the recommended values by Fixen et al. (2015) (40-60).

IE expresses the capacity of the plant to transform nutrients acquired from all sources (fertilizers and soil indigenous) into economic yield. IE numerical results for corn and wheat are shown in Figure 9e. According to Fixen et al. (2015), IE values of 30-90 are common in cereals and 55-65 are considered optimal. IE simulated values for corn are within the reported values for the entire range of $\mathrm{N}$ rates. In contrast, IE numerical results for wheat are out of the range described above $(<30)$ when fertilizer application rates are greater than $120 \%$. Poor internal nutrient conversion because of drought stress and heat stress may explain the out of range values. The good match between experimental data and simulated results regarding NUE suggests that SWAT can be a suitable tool for sustainable agriculture assessment.

In order to evaluate potential effects on soil and water quality, $\mathrm{NO}_{3}-\mathrm{N}$ leaching and runoff losses as $\mathrm{N}$ balance indicators were analysed. Numerical results of nitrate leached below the soil profile and nitrate contributed in surface runoff to a river reach in a wheat-soybean double-crop rotation HRU are shown in Figure 10a and 10b, respectively. As seen in both figures, the average annual nitrate exportations increase with higher fertilizer rates. $\mathrm{NO}_{3}-\mathrm{N}$ leaching and runoff losses are directly proportional to fertilizer rate until it reaches $120 \%$ and $80 \%$, respectively. For higher fertilizer applications, $\mathrm{NO}_{3}-\mathrm{N}$ leaching and runoff losses increase at a slightly higher rate. The correlation between leaching of nitrates in the root zone and nitrate concentrations in groundwater is difficult to determine because of the effects of other factors such as groundwater depth, 


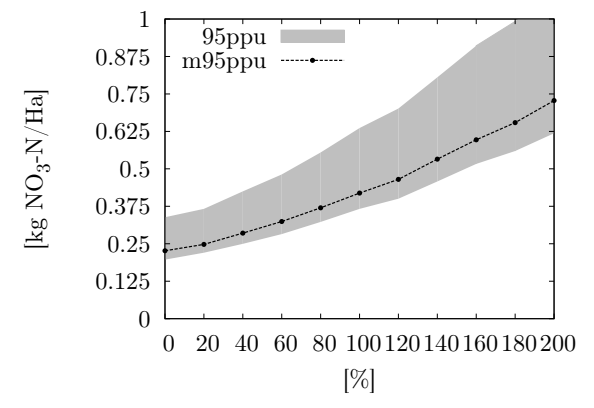

(a)

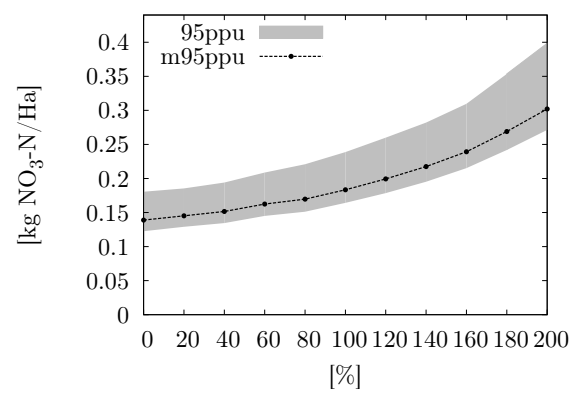

(b)

Figure 10: Wheat-soybean double-crop rotation HRU responses to scenarios of different fertilizer application rates. (a) Average annual $\mathrm{NO}_{3}-\mathrm{N}$ leached below the soil profile in the period 1998-2013. (b) Average annual $\mathrm{NO}_{3}-\mathrm{N}$ contributed in surface runoff to a river reach in the period 1998-2013.

lateral flow, and denitrification in the unsaturated zone (Akhavana et al., 2010; Paz et al., 2008). Moreover, no previous field data for CRLB are available for nitrate leaching nor nitrate concentration in groundwater. This result makes the calibration of simulated leaching or class ranges definition of SWAT results for this variable difficult, because not enough nitrate concentration data in groundwater is available for correlation analysis. More research under practical farming conditions is needed to achieve improved model performance concerning nitrogen leaching and its relation with groundwater contamination.

\section{Conclusions}

This work successfully explored the application of the SWAT model to the CRLB in the Pampas region, Argentina. It was demonstrated in this work that assembly of all the necessary input information to run the SWAT model in a basin with limited available data, such as the CRLB, is a difficult task. The analysis of field and remote-sensing data characterizing hydrology, water quality, soil types, land use/land cover, management practices, and crop yield, guarantee a comprehensive SWAT modeling approach. In order to avoid over- 
parameterization, OAT sensitivity analysis was first applied. After identifying a set of sensitive parameters and their range of sensitivity, the SUFI2 uncertainty analysis routine incorporated in SWAT-CUP tool was used for hydrology, nutrients and crop yield calibration. This analysis was performed in successive stages incorporating information about internal watershed behavior. The overall quality of the fit was satisfactory considering the input data limitations. River discharge and crop yield were well simulated. Once SWAT was calibrated and validated, different agricultural practice scenarios, corresponding to different fertilizer application rates were simulated. Eleven N/P fertilizer rates were selected to simulate the effect of $\mathrm{N}$ fertilizer on crop yield, plant uptake, and runoff and leaching losses. Different indices (PFP, AE, RE, IE and PE) were considered to assess nitrogen use efficiency. The good match between experimental data from the literature and model-simulated results concerning NUE indicates that the SWAT model can be a suitable tool for evaluating cropproduction systems in the study area. Nitrogen runoff and leaching losses as $\mathrm{N}$ balance indicators were also analysed to evaluate potential effects on soil and water quality. More research under practical farming conditions is needed to achieve improved model performance regarding $\mathrm{N}$ leaching and its relation with groundwater contamination. Overall, this work provides, for the first time in Argentina, a reliable tool to simulate yield response to soil quality and water availability capable to meet defined environmental targets to support decision making on planning public policies and private activities in the Pampas region, Argentina.

\section{Acknowledgements}

This research was supported by National Scientific and Technical Research Council of Argentina (CONICET) and partially funded by ANPCyT PICTPRH N ${ }^{\circ} 50$. The Secretary for Water Resources within the Ministry of Water and Environment of Córdoba Province provided assistance in monitoring field activities. Undergraduate students from Rosario National University, Gabriela 
Ludici and Ezequiel Manchó, helped digitizing the soil survey maps. The authors acknowledge Angel M. Martin Jr., USGS retired, for his technical edit of the manuscript, and two anonymous reviewers for helpful and constructive comments that contributed to improving the final version of this work.

\section{References}

Abbaspour, K.C., 2015. SWAT Calibration and Uncertainty Programs - A user manual. Swiss Federal Institute of Aquatic Science and Technology.

Abbaspour, K.C., Johnson, C.A., van Genchten, M., 2004. Estimating uncertain flow and transport parameters using a sequential uncertainty fitting procedure. Journal of Vadouse Zone 3, 1340-1352.

Abbaspour, K.C., Yang, J., Maximov, I., Siber, R., Bogner, K., Mieleitner, J., Zobrist, J., Srinivasan, R., 2007. Modelling hydrology and water quality in the pre-alpine/alpine Thur watershed using SWAT. Journal of Hydrology 333, 413-430. doi:10.1016/j.jhydrol.2006.09.014.

Acutis, M., Donatelli, M., 2003. Soilpar 2.0: software to estimate soil hydrological parameters and functions. European Journal of Agronomy, 373-377.

Akhavana, S., Abedi-Koupaia, J., Mousavia, S., Afyunib, M., Eslamiana, S., Abbaspourc, K.C., 2010. Application of SWAT model to investigate nitrate leaching in Hamadan-Bahar watershed, Iran. Agriculture, Ecosystems and Environment 139, 675-688.

Arnold, J.G., Allen, P.M., 1999. Automated methods for estimating baseflow and ground water recharge from streamflow records. Journal of the American Water Resources Association 35, 411-424. doi:10.1111/j.17521688.1999.tb03599.x.

Arnold, J.G., Allen, P.M., Muttiah, R.S., Bernhardt, G., 1995. Automated base flow separation and recession analysis techniques. Ground Water 33, 1010-1018. doi:10.1111/j.1745-6584.1995.tb00046.x. 
Arnold, J.G., Kiniry, J.R., Srinivasan, R., Williams, J.R., Haney, E.B., Neitsch, S.L., 2012a. Soil and water assessment tool - input/output file documentation - Version 2012. Technical Report 439. Texas Water Resources Institute.

Arnold, J.G., Moriasi, D.N., Gassman, P.W., Abbaspour, K.C., White, M.J., Srinivasan, R., Santhi, C., Harmel, R.D., van Griensven, A., van Liew, M.W., Kannan, N., Jha, M.K., 2012b. SWAT: model use, calibration and validation. Transactions of the ASABE 55, 1491-1508.

Arnold, J.G., Srinivasan, R., Muttiah, R.S., Williams, J.R., 1998. Large area hydrologic modeling and assessment Part i: model development. Journal of the American Water Resources Association 34, 73-89. doi:10.1111/j.17521688.1998.tb05961.x.

Arnold, J.G., Youssef, M.A., Yen, H., White, M.J., Sheshukov, A.Y., Sadeghi, A.M., Moriasi, D.N., Steiner, J.L., Amatya, D.M., Skaggs, R.W., Haney, E.B., Jeong, J., Arabi, M., Gowda, P.H., 2015. Hydrological processes and model representation: impact of soft data on calibration. Transactions of the ASABE 58, 1637-1660.

Bertoni, J.C., Ganancias, F., 2010. Hydrological behavior and design criteria of hydraulic structures in changing climate systems: considerations and case analysis. (In Spanish), in: Paoli, C.U., Malinow, G.V. (Eds.), Criterios para la determinación de crecidas de diseño en sistemas climáticos cambiantes, EdicionesUNL. Universidad Nacional del Litoral, Santa Fe, Argentina. pp. $7-22$.

Bressiani, D., Gassman, P.W., Fernandes, J., Garbossa, L., Srinivasan, R., Bonumá, N., Mendiondo, E., 2015. Review of soil and water assessment tool (SWAT) applications in Brazil: Challenges and prospects. International Journal of Agricultural and Biological Engineering 8, 9-35. doi:10.3965/j.ijabe.20150803.1765.

CGIARCSI, 2014. URL: http://www . cgiar-csi.org/data/srtm-90m-digital-elevation-database-v4-1. 
Chavez, P.S., 1996. Image-based atmospheric corrections - revisited and improved. Photogrammetric Engineering and Remote Sensing 62, 1025-1036.

Cibin, R., Sudheer, K.P., Chaubey, I., 2010. Sensitivity and identifiability of stream flow generation parameters of the SWAT model. Hydrological Processes 24, 1133-1148. doi:10.1002/hyp.7568.

Copperi, M., Mandolesi, M., Cantamutto, M., Ron, M., 2013. Comparative effectiveness of two nitrogen sources for corn fertilization. International Journal of Experimental Botany 82, 99-106.

Dile, Y.T., Srinivasan, R., 2014. Evaluation of CFSR climate data for hydrologic prediction in data-scarce watersheds: an application in the Blue Nile river basin. Journal of the American Water Resources Association 50, 1226-1241. doi:10.1111/jawr.12182.

Dobermann, A., 2007. Nutrient use efficiency - measurements and management, in: IFA International Workshop on Fertilizer Best Management Practices, Brussels, Belgium. pp. 1-28.

Douglas-Mankin, K.R., Srinivasan, R., Arnold, J.G., 2010. Soil and water assessment tool (SWAT) model: Current developments and applications. Transactions of the ASABE 53, 1423-1431.

FAO, 2015. URL: http://faostat3.fao.org/home/E.

Fixen, P., Brentrup, F., Bruulsema, T., Garcia, F., Norton, R., Zingore, S., 2015. Nutrient/fertilizer use efficiency: measurements, current situation and trends, in: Drechsel, P., Heffer, P., Magen, H., Mikkelsen, R., Wichelns, D. (Eds.), Managing water and fertilizer for sustainable agricultural intensification. IFA, IWMI, PINI and IPI. chapter 2, p. 270.

Fuka, D.R., Walter, M.T., MacAlister, C., Degaetano, A.T., Steenhuis, T.S., Easton, Z.M., 2014. Using the Climate Forecast System Reanalysis as weather input data for watershed models. Hydrological Processes 28, 5613-5623. doi:10.1002/hyp.10073. 
Gallagher, K.P., Irwin, A., Koleski, K., 2012. The new banks in town: Chinese finance in Latin America. Report. Inter-American Dialogue. 1211 Connecticut Avenue, NW, Suite 510 Washington, DC 20036.

Galloway, J.N., Townsend, A.R., Erisman, J.W., Bekunda, M., Cai, Z., Freney, J.R., Martinelli, L.A., Seitzinger, S.P., Sutton, M.A., 2008. Transformation of the nitrogen cycle: Recent trends, questions, and potential solutions. Science 320, 889-892. doi:10.1126/science.1136674.

García, F., Taboada, M., Sanjuan, M., Picone, L., 2013. Nitrogen in Argentine agriculture. Alternatives to increase the use efficiency in grain crops and to mitigate nitrous oxide emissions. (In Spanish). Technical Report. International Plant Nutrition Institute.

Gassman, P.W., Reyers, M.R., Green, C.H., Arnold, J.G., 2007. The soil and water assessment tool: historical development, applications, and future research directions. Transactions of the ASABE 50, 1211-1250.

van Grinsven, H.J.M., Erisman, J.W., de Vries, W., Westhoek, H., 2015. Potential of extensification of European agriculture for a more sustainable food system, focusing on nitrogen. Environmental Research Letters 10. doi:http://dx.doi.org/10.1088/1748-9326/10/2/025002.

GSF, 2014. URL: http://www.santafe.gov.ar.

Havrylenko, S., Bodoque, J., Srinivasan, R., Zucarelli, G., Mercuri, P., 2016. Assessment of the soil water content in the pampas region using SWAT. Catena 137, 298-309. doi:10.1016/j.catena.2015.10.001.

INTA, 1988. Soil maps of the Argentine Republic. (In Spanish). Technical Report. Instituto de Tecnología Agropecuaria. Buenos Aires.

Jha, M., 2009. Hydrologic simulations of the Maquoketa river watershed using SWAT. Technical Report work paper 492. Iowa State University. 
Jha, M., Gassman, P.W., Secchi, S., Gu, R., Arnold, J.G., 2004. Effect of watershed subdivision on SWAT flow, sediment and nutrient predictions. Journal of the American Water Resources Association 40, 811-825. doi:10.1111/j.17521688.2004.tb04460.x.

Krysanova, V., White, M., 2015. Advances in water resources assessment with SWAT-an overview. Hydrological Sciences Journal 60, 771-783. doi:10.1080/02626667.2015.1029482.

Kumar, S., Watson, B.M., Putz, G., Prepas, E.E., 2011. Modelling nitrogen in streamflow from Boreal forest watersheds in Alberta, Canada using SWAT, in: 2011 International SWAT Conference, University of Castilla La Mancha, Toledo, Spain.

Martinez, J., Galanti, J., Landriscini, M., 2015. Nitrogen use efficiency for wheat in semiarid region of Buenos Aires (Argentina). Effects of the dose and timing application. AgriScientia 3, 15-27.

Meals, D.W., Richards, R.P., Dressing, S.A., 2013. Pollutant Load Estimation for Water Quality Monitoring Projects. Technical Report 8. U.S. Environmental Protection Agency.

Moscatelli, G., Pazos, M., 2000. Soils of Argentina - nature and use, in: Kheoruenromne, I., Theerawong, S. (Eds.), Proceedings of International Symposium on Soil Science: Accomplishments and Changing Paradigm towards the 21st Century, Bangkok. pp. 81-92.

Mueller, D.S., Wagner, C.R., 2009. Measuring Discharge with Acoustic Doppler Current Profilers from a Moving Boat. Techniques and Methods 3-A22. USGS.

Neitsch, S.L., Arnold, J.G., Kiniry, J.R., Williams, J.R., 2011. Soil and water assessment tool - Theoretical documentation - Version 2009. Technical Report 406. Texas Water Resources Institute.

Olivera, F., Valenzuela, M., Srinivasan, R., Choi, J., Cho, H., Koka, S., Agrawal, A., 2006. ArcGIS-SWAT: a geodata model and GIS interface for 
SWAT. Journal of the American Water Resources Association 42, 295-309. doi:10.1111/j.1752-1688.2006.tb03839.x.

Paz, J.M.D., Delgado, J.A., Ramos, C., Shaffer, M.J., Barbarick, K.K., 2008. Use of a new GIS nitrogen index assessment tool for evaluation of nitrate leaching across a Mediterranean region. Journal of Hydrology 365, 183-194. doi:10.1016/j.jhydrol.2008.11.022.

Ray, D.K., Mueller, N.D., West, P.C., Foley, J.A., 2013. Yield trends are insufficient to double global crop production by 2050. PLoS ONE 8. doi:10.1371/journal.pone.0066428.

Rice, E.W., Baird, R.B., Eaton, A.D., Clesceri, L.S., 2012. Standard methods for the examination of water and wastewater. 22 ed., American Public Health Association, American Water Works Association and Water Environment Federation.

Richards, J.A., 1986. Remote Sensing Digital Image Analysis. Springer-Verlag.

Rocha, J., Roebeling, P., Rial-Rivas, M.E., 2015. Assessing the impacts of sustainable agricultural practices for water quality improvements in the Vouga catchment (Portugal) using the SWAT model. Science of the Total Environment 536, 48-58. doi:10.1016/j.scitotenv.2015.07.038.

Schaap, M.G., Leij, F.J., van Genuchten, M.T., 2001. Rosetta: a computer program for estimating soil hydraulic parameters with hierarchical pedotransfer functions. Journal of Hydrology 251, 163-176. doi:10.1016/S00221694(01)00466-8.

Schmalz, B., Fohrer, N., 2009. Comparing model sensitivities of different landscapes using the ecohydrological SWAT model. Advances in Geosciences 21, $91-98$.

Seibert, J., McDonnell, J.J., 2002. On the dialog between experimentalist and modeler in catchment hydrology: use of soft data for mul- 
ticriteria model calibration. Water Resources Research 38, 23-1-23-14. doi:10.1029/2001WR000978.

Solbrig, O.T., 1996. Towards a sustainable Pampa agriculture: Past performance and prospective analysis. Working paper 96/97-6. The David Rockefeller Center for Latin American Studies. Harvard University, MA, US.

SSRH, 2010. Atlas of basins and surface water regions of the Argentine Republic. (In Spanish). Technical Report. Subsecretaría de Recursos Hídricos. Buenos Aires.

Tilman, D., Cassman, K.G., Matson, P.A., Naylor, R., Polasky, S., 2002. Agricultural sustainability and intensive production practices. Nature 418, 671677. doi:10.1038/nature01014.

Tsonis, A.A., Elsner, J.B. (Eds.), 2007. Nonlinear dynamics in geosciences. Springer.

Tuppad, P., Douglas-Mankin, K.R., Lee, T., Srinivasan, R., Arnold, J.G., 2011. SWAT hydrologic/water quality model: Extended capability and wider adoption. Transactions of the ASABE 54, 1677-1684.

Tuppad, P., Kannan, N., Srinivasan, R., Rossi, C.G., Arnold, J.G., 2010. Simulation of agricultural management alternatives for watershed protection. Water Resources Management 24, 3115-3144. doi:10.1007/s11269-010-9598-8.

USGS, 2015. URL: http://eros.usgs.gov.

Velasco, J., Rozas, H., Echeverría, H., Barbieri, P., 2012. Optimizing fertilizer nitrogen use efficiency by intensively managed spring wheat in humid regions: effect of split application. Canadian Journal of Plant Science 92, 847-856.

Venencio, M., 2008. The natural recharge to the free aquifer and its linkage with the regional climatic variability. (In Spanish). Ph.D. thesis. Universidad Nacional de Córdoba. 
White, M.J., Harmel, R.D., Arnold, J.G., Williams, J.R., 2012. SWAT check: a screening tool to assist users in the identification of potential model application problems. Journal of Environmental Quality 43, 208-214. doi:10.2134/jeq2012.0039.

Yen, H., 2012. Confronting input, parameter, structural, and measurement uncertainty in multi-site multiple responses watershed modeling using Bayesian inferences. Ph.D. thesis. Colorado State University. Fort Collins.

Yen, H., Bailey, R.T., Arabi, M., Ahmadi, M., White, M.J., Arnold, J.G., 2014. The role of interior watershed processes in improving parameter estimation and performance of watershed models. Journal of Environmental Quality 43, 1601-1613. doi:10.2134/jeq2013.03.0110.

Young, S., 2006. Agriculturalization as a syndrome: a comparative study of agriculture in Argentina and Australia. Medio Ambiente y Desarrollo 125. CEPAL. Santiago, Chile.

Zimmermann, E.D., Basile, P.A., 2008. Use of pedotransfer functions for the estimation of hydraulic parameters in silty soils (Argentinean plain). (In Spanish). Boletín Geológico y Minero 119, 71-80. 


\section{Graphical abstract}

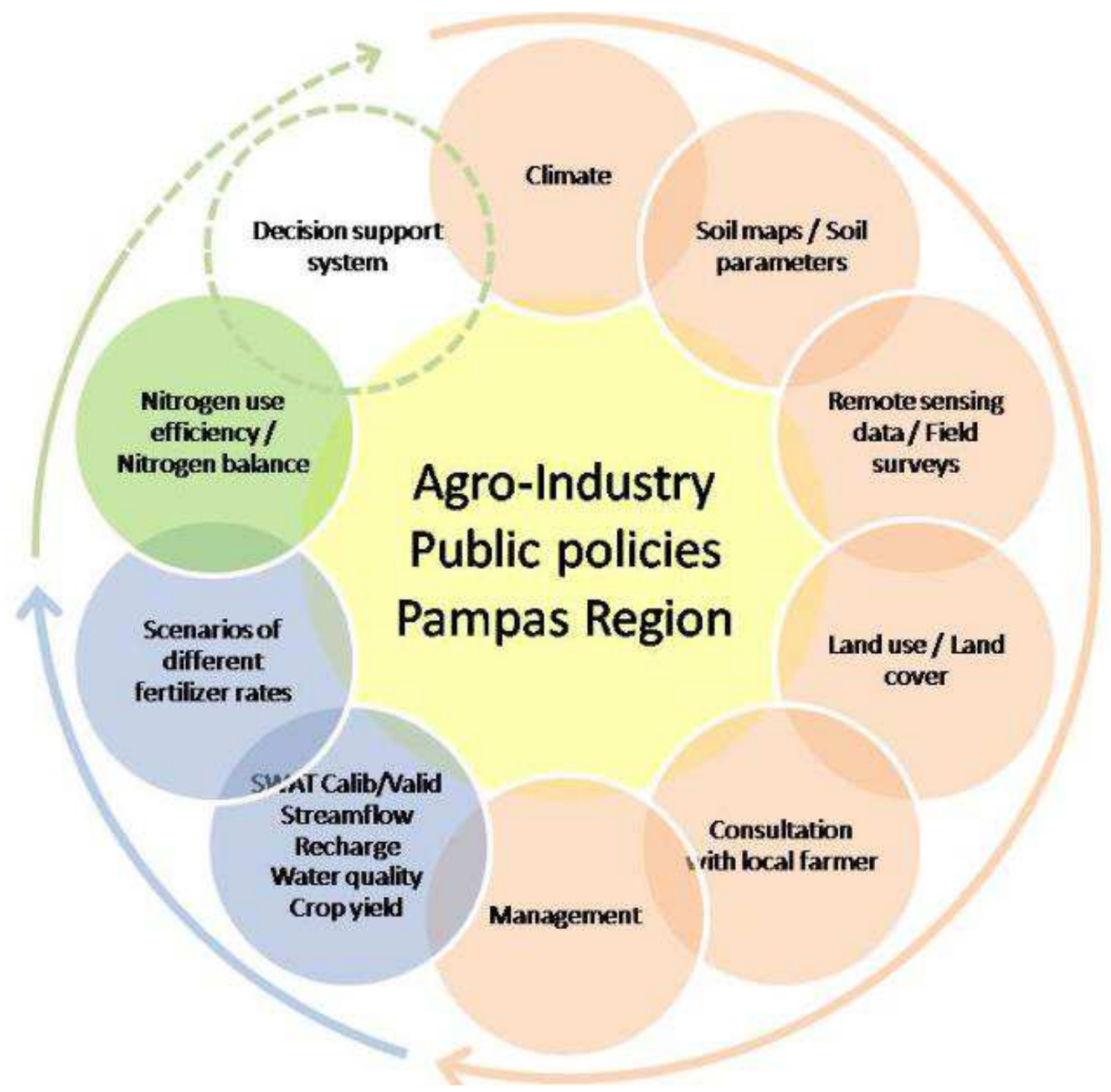

